\title{
Palliative care training and associations with burnout in oncology fellows
}

\author{
Sarah Schellhorn Mougalian, MD, ${ }^{1}$ David S. Lessen, $\mathrm{MD},{ }^{2}$ Randy L. Levine, MD, ${ }^{3}$ \\ Georgia Panagopoulos, PhD, ${ }^{4}$ Jamie H. Von Roenn, MD, ${ }^{5}$ Robert M. Arnold, MD, ${ }^{6}$ \\ Susan D. Block, MD, ${ }^{7,8}$ and Mary K. Buss, MD, $\mathrm{MPH}^{8,9}$ \\ ${ }^{1}$ M. D. Anderson Cancer Center, Houston, Texas; ${ }^{2}$ Southeast Florida Hematology Group, Ft. Lauderdale; ${ }^{3}$ Blood Bank and \\ Transfusion Services; ${ }^{4}$ Lenox Hill Hospital, New York, New York; ${ }^{5}$ Division of Hematology/Oncology, Robert H. Lurie \\ Comprehensive Cancer Center, Northwestern University and Feinberg School of Medicine, Chicago, Illinois; ${ }^{6}$ Leo H. Criep \\ Professor of Patient Care, Institute for Doctor-Patient Communication, Section of Palliative Care and Medical Ethics, \\ University of Pittsburgh Hospital, Pennsylvania; ${ }^{7}$ Division of Psychosocial Oncology and Palliative Care, Dana-Farber Cancer \\ Institute and Brigham and Women's Hospital, Boston, Massachusetts; ${ }^{8}$ Harvard Medical School, Boston, Massachusetts; and \\ ${ }^{9}$ Palliative Care Consultation Service, Division of Hematology-Oncology, Beth Israel Deaconess Medical Center, Boston, \\ Massachusetts
}

Background Burnout among physicians can lead to decreased career satisfaction, physical and emotional exhaustion, and increased medical errors. In oncologists, high exposure to fatal illness is associated with burnout.

Methods The Maslach Burnout Inventory, measuring Emotional Exhaustion (EE), Depersonalization (DP), and Personal Accomplishment (PA), was administered to second-year US oncology fellows. Bivariate and multivariate analyses explored associations between burnout and fellow demographics, attitudes, and educational experiences.

Results A total of 254 fellows out of 402 eligible US fellows responded (63.2\%) and $24.2 \%$ reported high EE, $30.0 \%$ reported high DP, and $26.8 \%$ reported low PA. Over half of the fellows reported burnout in at least one domain. Lower EE scores were associated with the fellows' perceptions of having received better teaching, explicit teaching about certain end-of-life topics, and receipt of direct observation of goals-of-care discussions. Fellows who reported better overall teaching quality and more frequent observation of their skills had less depersonalization. Fellows who felt a responsibility to help patients at the end of life to prepare for death had higher PA.

Limitations This survey relies on the fellows' self-reported perceptions without an objective measure for validation. Factors associated with burnout may not be causal. The number of analyses performed raises the concern for Type I errors; therefore, a stringent $P$ value (0.01) was used.

Conclusions Burnout is prevalent during oncology training. Higher-quality teaching is associated with less burnout among fellows. Fellowship programs should recognize the prevalence of burnout among oncology fellows as well as components of training that may protect against burnout.

\section{Burnout}

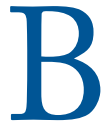

urnout has been described in the medical profession. Burnout is defined as "exhaustion of physical or emotional strength usually as a result of prolonged stress or frustration". ${ }^{1}$ Burnout is associated with distancing oneself from one's work, reduced empathy, and a feeling of reduced personal accomplishment. ${ }^{2}$

Manuscript received May 24, 2012; accepted September 26, 2012. Correspondence Sarah Schellhorn Mougalian, MD, Hematology/Medical Oncology Fellow, MD Anderson Cancer Center; 1515 Holcombe Blvd., Unit 0010, Houston, TX 770304000 (schellhorn@post.harvard.edu).

Disclosures The authors have completed and submitted the ICMJE Form for Disclosure of Potential Conflicts of Interest and none were reported.

J Support Oncol 2013;1 1:95-102 @ 2013 Frontline Medical Communications DOI: 10.12788/i.suponc.0001
Burnout is well described among physicians and has implications for both the personal wellbeing of physicians and the patients they treat. Among physicians, burnout is associated with family and marital problems, physical and emotional exhaustion, insomnia, increased rates of substance abuse, and even increased risk of suicide. $^{3}$ Physicians who are "burned out" are more likely to behave unethically and cross boundaries and less likely to communicate effectively with their patients. ${ }^{4}$ Burnout leads to higher rates of inappropriate prescribing and medical errors, which puts patients at risk for harm. ${ }^{4-6}$

Even during medical training, burnout exists and has important implications. More than $75 \%$ of internal medicine residents met the criteria for burn- 
out; these residents reported more episodes of suboptimal patient care and less career satisfaction than did those residents without burnout. ${ }^{6}$ Among US medical students, burnout was associated with unprofessional conduct and less altruistic views regarding physicians' roles in society. ${ }^{7}$

Burnout also has been described among oncologists. In 1991, a survey demonstrated that over half (58\%) of medical oncologists had experienced burnout at least once during their careers. ${ }^{8}$ Other investigators found the prevalence of burnout among oncologists ranged from 34\%$69 \% .^{9-12}$ Aside from lack of personal time, which was named as a contributor to burnout in $57 \%$ of the respondents in the initial survey, the two most-cited reasons for burnout were "continuous exposure to fatal illness" (53\%) and "frustration with limited therapeutic success" (45\%). ${ }^{8,12}$ Another common contributor to burnout was "negative work events", such as struggling over end-of-life (EOL) issues or frequent patient deaths. ${ }^{13}$ Thus, exposure to critical and life-threatening illnesses while caring for patients in the setting of advanced or terminal disease appears to be a critical factor associated with burnout in oncologists. ${ }^{5,11,14-18}$

Finally, insufficient training in communication and lack of education about EOL care are also associated with frustration and burnout. For example, in a study of 476 oncologists and palliative care specialists, those who felt insufficiently trained in communication reported higher levels of depersonalization (DP) and lower levels of personal accomplishment (PA). ${ }^{18-21}$

Based on the available literature, it would seem that oncology fellows are at high risk for burnout. They are medical trainees, learning to care for patients whose disease is often terminal. In addition to the high exposure to fatal illness, they are learning how to prescribe chemotherapeutic agents, which have high toxicity and often limited therapeutic efficacy in advanced cancer. Oncology fellows report considerable gaps in their EOL education, ${ }^{22}$ suggesting they have not fully honed their EOL skills. Thus, we hypothesized that oncology fellows would have a high prevalence of burnout.

To our knowledge, no previous study has examined burnout among oncology fellows, our future oncologists, nor has any study examined the relationship between burnout and EOL-care training among these fellows. We hypothesize that perceived quality of education and positive attitudes about EOL care during fellowship would correlate with lower rates of burnout among oncology trainees. Thus, we sought to determine the prevalence and predictors of burnout among oncology fellows in the United States and to explore the relationship between burnout and EOL attitudes and education among these fellows.

\section{Methods}

\section{Study sample and recruitment}

Second-year fellows enrolled in either a medical oncology or a hematology/medical oncology fellowship program in the United States were surveyed. All second-year fellows, according to a list provided by the American Medical Association, were recruited (413 fellows); only secondyear fellows who participated in the pilot study $(n=11)$ were excluded, for a total of 402 eligible fellows. The survey was completed during the second half of the academic year to capture fellows who had completed the bulk of clinical training and those enrolled in both two- and three-year programs. Details of recruitment for the survey are reported elsewhere. ${ }^{22}$

\section{The instrument}

The 104 items on this survey were adapted from a national telephone survey developed for medical students, residents, and faculty. ${ }^{23}$ The original items were derived from the content of focus groups of medical students, residents and faculty and a review of the literature. The final survey addressed nine domains: respondent characteristics (15 items); quality and quantity of teaching within fellowship training (11 items); curriculum (14 items); observation and feedback (6 items); knowledge (4 items); caring for the dying (16 items); preparation (7 items); attitudes (9 items); and burnout (the 22-item Maslach Burnout Inventory [MBI]). ${ }^{3}$ Further details of the first 8 domains have been previously reported. ${ }^{22}$

We report on burnout as our primary endpoint. We also explore the relationship/associations between burnout and the following variables: respondent demographics, perceptions of quality teaching within their fellowship, institutional and individual attitudes toward death and dying, and the fellows' perceived preparedness to care for a patient at EOL. In addition, the relationships between burnout and the explicit (that which is consciously and intentionally presented to a student) and implicit (the norms and values of an institution that are indirectly imparted, also known as the "hidden curriculum") curricula within fellowships were examined.

A copy of the instrument is available on request. The study was exempted from review by the Institutional Review Board at Dana Farber Cancer Institute Office for Protection of Human Subjects.

\section{Maslach Burnout Inventory}

The MBI modified for medical practice was included under the survey section entitled "Job-Related Feelings". ${ }^{3}$ The MBI is the standard for measuring burnout. The 
TABLE 1 Respondents and all oncology fellows

\begin{tabular}{lccc} 
& Respondents & All Oncology Fellows & P value \\
Male n (\%)* & $106(52.2 \%)$ & $252(62.1 \%)$ & .13 \\
\hline Age mean (SD)* & $31.7(4.4)$ & $31.7(4.1)$ & .88 \\
White (vs non-White) n (\%)* & $125(61.6 \%)$ & $234(59.1 \%)$ & .71 \\
US Medical School (vs non-US) (\%) & $130(63.7 \%)$ & $244(59.7 \%)$ & .54 \\
\hline
\end{tabular}

* Gender, age, and ethnicity data not available for 51 participants; ${ }^{\dagger}$ Medical school data not available for 50 participants.

MBI Human Services Survey (HSS) contains 22 statements, each addressing one of the components of burnout (emotional exhaustion [EE, 9 items], depersonalization [DP, 5 items], and decreased personal accomplishment [PA, 8 items]). Burnout in each domain is measured as a continuous variable and is defined as high levels of $\mathrm{EE}$ (for example, "I feel like I'm at the end of my rope"), high levels of DP (for example, "I feel I treat some patients as if they were impersonal objects") or low levels of PA (for example, "I feel I'm positively influencing other people's lives through my work"). The respondent rates how often a particular statement reflects how he feels about his job from 0 (never) to 6 (every day). Three separate summative scores, rather than one aggregate, are calculated for each respondent, in accordance with recommendations from the survey developers. High levels of burnout were defined as follows: $\mathrm{EE} \geq 27, \mathrm{DP} \geq 10$, and $\mathrm{PA} \leq 33$; low levels of burnout were defined as $\mathrm{EE} \leq 18, \mathrm{DP} \leq 5$, and $\mathrm{PA} \geq 40$, per the MBI Manual. The instrument was used with permission. ${ }^{3}$

\section{Statistical analysis}

Bivariate and multivariate analyses were used to find associations between burnout and fellow demographics, attitudes, and educational experiences. For dichotomous variables, Chi-square or Fisher exact tests were used. For continuous variables, the dependent-groups Student $t$ test was used for data with normal distribution, and the Wilcoxon signed rank test was used for data with a nonnormal distribution. To reduce the probability of Type I errors from multiple testing, a more stringent alpha level was used. Associations were not considered statistically significant unless $P \leq .01$. When significant associations were observed between an independent variable of interest and one of the burnout domains (EE, DP, or PA) on bivariate analysis, a multiple logistic regression analysis was performed. All independent variables associated with a $P$ value of $\leq .05$ were entered into the model. All analyses were conducted using SAS version 9.1 (SAS Institute, Cary, NC).

\section{Results}

\section{Respondents and Prevalence of Burnout}

A total of 254 second-year hematology/medical oncology and medical oncology fellows responded out of 402 eligible fellows, for an overall response rate of $63.2 \%$. Fellows were largely white (61.6\%); other races included Asian (27.1\%), African American (3.9\%), Hispanic (3.0\%), Pacific Islander (0.5\%), and other (3.9\%). Respondents were mostly married (74.8\%), and graduated from US medical schools (63.7\%); there were similar numbers of male and female respondents $(52.2 \%$ male). Of these respondents, $69 \%$ had exposure to a palliative care specialty service during their training. Demographics did not differ between those who completed the survey and the larger pool of 402 eligible fellows (Table 1).

Burnout was common in our sample. The mean EE score was $19.1 \pm 10.0$, the mean DP score was $6.78 \pm$ 5.1, and the mean PA score was $36.72 \pm 7.53$. Among respondents, $24.2 \%$ reported high EE, $28.3 \%$ reported high DP, and 26.8\% reported low PA (Figure 1). Over half of the oncology fellows reported a high level of burnout in at least one of the 3 areas (32.9\% in one area, $16.5 \%$ in 2 areas, and $5.5 \%$ in all 3 areas).

\section{Associations with emotional exhaustion}

Significant associations with lower EE scores are shown in Table 2. Fellows who perceived higher overall quality of teaching in fellowship and those who reported that faculty had observed goals-of-care discussions had significantly lower EE scores after multivariate analysis. Fellows who felt prepared to address spiritual issues at EOL and those who felt prepared to manage their own feelings around a patient's illness and dying had lower EE; these associations persisted after multivariate analysis. Respondents who self-reported their race as white had significantly higher EE.

\section{Associations with depersonalization}

Younger fellows had higher DP scores $(r=0.19, P=$ .007). Table 3 depicts the factors associated with lower 


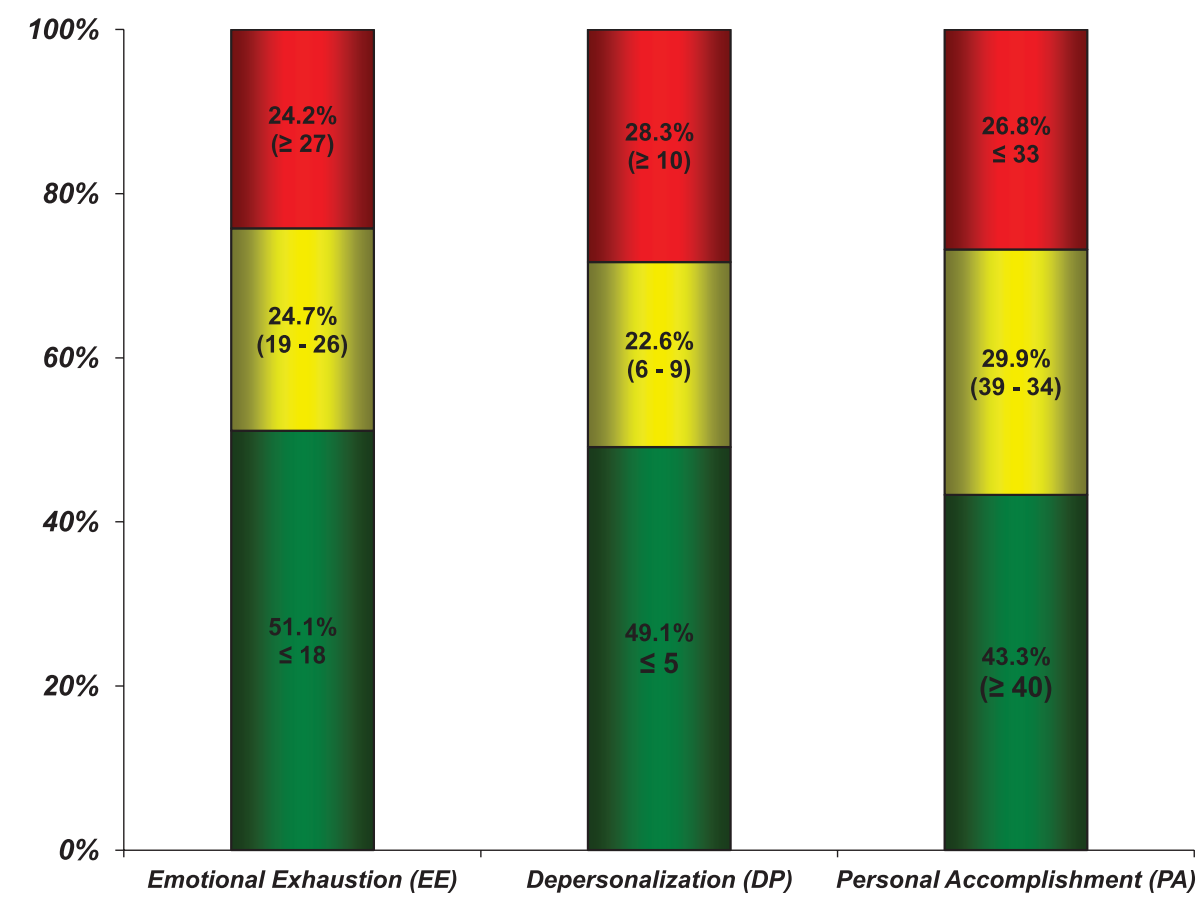

FIGURE 1 Rates and Level of Burnout among Oncology Fellows. Red = High levels of burnout; Yellow = Average levels of burnout; Green = Low levels of burnout. Percentages of respondents in each category are shown. Numbers in parentheses represent the categorization scores for each domain. For EE and DP, higher scores demonstrate higher levels of burnout; for PA, lower scores demonstrate higher levels of burnout.

DP scores. After adjusting for those variables that were significant on bivariate analysis, 2 factors remained significantly associated with higher DP scores: self-reported white race and dreading dealing with the emotional distress of a dying patient's family members.

\section{Associations with personal accomplishment}

All factors associated with higher PA scores can be viewed in Table 4. Fellows who believed that physicians have a responsibility to help patients at the EOL to prepare for death had significantly higher PA, an association that persisted after multivariate analysis.

\section{Discussion}

We report on the prevalence of burnout among oncology fellows and association between burnout and the fellows' attitudes and perceived EOL training. Burnout was quite prevalent among oncology fellows, with over half of the oncology fellows exhibiting high levels of burnout in at least one domain. The only other studies of US oncology practitioners are older and do not use as robust a measure of burnout; however, both indicate that burnout is a prevalent challenge. ${ }^{8,24}$ Our study demonstrates that high levels of burnout also exist during training, even before young oncologists enter the workforce. This suggests that burnout, known to be a major barrier to career satisfaction, may begin during the early stages of training. Fel- lows who perceived that their programs provided a high overall quality of teaching reported less burnout in all 3 measures: EE, DP, and PA. Furthermore, certain components of fellowship education, which are markers of good palliative care education, also were associated with less burnout in all 3 domains, such as: explicit teaching on opioid rotation, when to refer a patient to hospice, and being observed by an attending oncologist leading a goalsof-care discussion. While our results support the hypothesis that good EOL training is associated with less burnout, more investigation is needed to determine causality, for example, if concerted efforts to provide more palliative care training protect against burnout.

An institution's so-called "hidden curriculum" may have powerful effects on trainees' career satisfaction. In our study, the single factor found to be significantly associated with fellows' sense of PA was the belief that physicians have the responsibility to help patients at the EOL prepare for death. The few fellows who responded that they did not have this responsibility had significantly lower PA than their colleagues. These fellows may view their roles as physicians much more narrowly; EOL care and preparing a patient for dying might be deemed outside of the realm of their professional role, and death of a patient could be construed as failure. Teaching this responsibility is not likely a conscious component of oncology fellowship curricula; however, it is modeled by at- 
TABLE 2 Oncology fellow responses associated with emotional exhaustion

\begin{tabular}{|c|c|c|}
\hline & Mean \pm Std Dev & $\begin{array}{l}\text { t score, P-value } \\
\text { (bivariate) }\end{array}$ \\
\hline \multicolumn{3}{|l|}{ Race/Ethnicity } \\
\hline White $(\mathrm{n}=120)$ & $20.8 \pm 9.8$ & \multirow{2}{*}{$\begin{array}{l}t=-3.4 \\
P=.0008^{*}\end{array}$} \\
\hline Non-White $(\mathrm{n}=75)$ & $15.9 \pm 9.6$ & \\
\hline \multicolumn{3}{|l|}{ Preparedness to address spiritual issues at EOL } \\
\hline Very well, Moderately well $(n=116)$ & $17.1 \pm 9.1$ & \multirow{2}{*}{$\begin{array}{l}t=-0.57 \\
P=.0030^{*}\end{array}$} \\
\hline Not very well, Not well at all ( $n=112)$ & $21.0 \pm 10.5$ & \\
\hline \multicolumn{3}{|c|}{ Prepared to manage own feelings about a patient's illness and dying } \\
\hline Very well, Moderately well $(n=175)$ & $17.7 \pm 9.6$ & \multirow{2}{*}{$\begin{aligned} t & =3.87 \\
P & =.0001 *\end{aligned}$} \\
\hline Not very well, Not well at all $(n=53)$ & $23.6 \pm 10.2$ & \\
\hline \multicolumn{3}{|c|}{$\begin{array}{l}\text { I dread having to deal with the emotional distress of family members of a } \\
\text { patient at the EOL }\end{array}$} \\
\hline Completely disagree, Generally disagree $(n=155)$ & $17.8 \pm 9.7$ & \multirow{2}{*}{$\begin{aligned} t & =-3.12 \\
P & =.0021\end{aligned}$} \\
\hline Generally agree, Completely agree $(n=69)$ & $22.2 \pm 10.4$ & \\
\hline \multicolumn{3}{|l|}{ I feel guilty after a death. } \\
\hline Completely disagree, Generally disagree $(n=188)$ & $18.3 \pm 10.0$ & \multirow{2}{*}{$\begin{aligned} t & =-2.89 \\
P & =.004\end{aligned}$} \\
\hline Generally agree, Completely agree $(n=36)$ & $23.5 \pm 9.4$ & \\
\hline \multicolumn{3}{|l|}{ Overall quality of teaching in fellowship } \\
\hline Very Good, Excellent ( $n=138$ ) & $17.0 \pm 9.2$ & \multirow{2}{*}{$\begin{array}{l}t=4.04 \\
P \leq .0001\end{array}$} \\
\hline Poor, Fair, Good ( $\mathrm{n}=90$ ) & $22.3 \pm 10.3$ & \\
\hline \multicolumn{3}{|c|}{ Faculty ability to discuss chemotherapy side effects (as perceived by the fellow) } \\
\hline Very Good, Excellent ( $\mathrm{n}=186$ ) & $18.1 \pm 9.7$ & \multirow{2}{*}{$\begin{aligned} t & =3.11 \\
P & =.0021\end{aligned}$} \\
\hline Poor, Fair, Good ( $n=41)$ & $23.4 \pm 10.7$ & \\
\hline \multicolumn{3}{|l|}{ Number of observed goals of care discussions } \\
\hline$\geq 1(\mathrm{n}=182)$ & $17.9 \pm 9.8$ & \multirow{2}{*}{$\begin{aligned} t & =3.95 \\
P & =.0001\end{aligned}$} \\
\hline None $(n=40)$ & $24.7 \pm 9.6$ & \\
\hline \multicolumn{3}{|l|}{ Explicit teaching on opioid rotation } \\
\hline Yes $(n=77)$ & $16.7 \pm 9.7$ & \multirow{2}{*}{$\begin{aligned} t & =2.8 \\
P & =.0056\end{aligned}$} \\
\hline No $(n=148)$ & $20.6 \pm 9.8$ & \\
\hline \multicolumn{3}{|l|}{ Explicit teaching on when to refer patients to hospice } \\
\hline Yes $(n=144)$ & $17.8 \pm 9.3$ & \multirow{2}{*}{$\begin{aligned} t & =2.73 \\
P & =.006\end{aligned}$} \\
\hline No $(n=83)$ & $21.5 \pm 10.6$ & \\
\hline \multicolumn{3}{|c|}{ Implicit teaching that advance care planning is a routine part of care } \\
\hline A lot, A moderate amount $(n=69)$ & $22.7 \pm 11.0$ & \multirow{2}{*}{$\begin{aligned} t & =3.52 \\
P & =.0005\end{aligned}$} \\
\hline A little, Not at all $(n=156)$ & $17.7 \pm 9.1$ & \\
\hline
\end{tabular}

Higher scores denote higher emotional exhaustion (more burnout).

$P<.01$ was considered statistically significant.

* $=$ multivariate $P<.01$.

tending physicians in their interactions with patients at the EOL. The degree to which oncologists in a particular institution subscribe to the belief that they are responsible for the transition to EOL is a part of the hidden curriculum. ${ }^{25}$ Fostering this belief within an oncology training program, and encouraging fellows to help patients prepare for death, could be pivotal to the development of feelings of PA among the fellows, especially when chemotherapeutic agents would have minimal efficacy. Encouraging or requiring home visits for patients on hospice and rotating with palliative care services (where available) might foster the expectation that preparing patients and families for the dying process is a part of an oncologist's core skill set. 
TABLE 3 Oncology fellow responses associated with depersonalization

\begin{tabular}{|c|c|c|}
\hline & Mean \pm Std Dev & $\begin{array}{c}\text { t score, P-value } \\
\text { (bivariate) }\end{array}$ \\
\hline \multicolumn{3}{|l|}{ Race/Ethnicity } \\
\hline White $(n=119)$ & $7.3 \pm 5.0$ & \multirow{2}{*}{$\begin{aligned} t & =-2.68 \\
P & =.0081^{*}\end{aligned}$} \\
\hline Non-White $(\mathrm{n}=75)$ & $5.4 \pm 4.8$ & \\
\hline \multicolumn{3}{|c|}{$\begin{array}{l}\text { I dread having to deal with the emotional distress of family members } \\
\text { of a patient at the end of life. }\end{array}$} \\
\hline Completely disagree, Generally disagree $(n=157)$ & $5.8 \pm 4.6$ & \multirow{2}{*}{$\begin{array}{l}t=-4.78 \\
P<.0001^{* *}\end{array}$} \\
\hline Generally agree, Completely agree $(n=65)$ & $9.2 \pm 5.5$ & \\
\hline \multicolumn{3}{|l|}{ Overall quality of teaching in fellowship } \\
\hline Very Good, Excellent ( $\mathrm{n}=138$ ) & $6.0 \pm 4.9$ & \multirow{2}{*}{$\begin{array}{l}t=2.84 \\
P=.0049\end{array}$} \\
\hline Poor, Fair, Good ( $n=88$ ) & $8.0 \pm 5.2$ & \\
\hline \multicolumn{3}{|l|}{ Number of observed goals of care discussions } \\
\hline$\geq 1(\mathrm{n}=180)$ & $6.2 \pm 4.9$ & \multirow{2}{*}{$\begin{aligned} t & =3.36 \\
P & =.0009\end{aligned}$} \\
\hline None $(n=41)$ & $9.1 \pm 5.5$ & \\
\hline \multicolumn{3}{|l|}{ Number of observed bone marrow biopsies } \\
\hline$\geq 1(n=207)$ & $6.5 \pm 5.0$ & \multirow{2}{*}{$\begin{aligned} t & =3.48 \\
P & =.0006\end{aligned}$} \\
\hline None $(n=16)$ & $11.0 \pm 4.6$ & \\
\hline \multicolumn{3}{|l|}{ Explicit teaching on opioid rotation } \\
\hline Yes $(\mathrm{n}=77)$ & $5.4 \pm 4.4$ & \multirow{2}{*}{$\begin{aligned} t & =3.17 \\
P & =.0017\end{aligned}$} \\
\hline No $(n=146)$ & $7.6 \pm 5.3$ & \\
\hline
\end{tabular}

Higher scores denote higher depersonalization (more burnout).

$P<.01$ was considered statistically significant.

** = multivariate $P<.001 ; *$ multivariate $P<.01$

Personal attitudes about EOL care were associated with burnout during fellowship. Specifically, feeling prepared to manage one's own feelings about a patient's illness and dying, being able to handle the emotional distress of family members, and absolving oneself of guilt surrounding the death of a patient were associated with lower levels of burnout. Specific forums for fellows to manage personal feelings surrounding death and dying, such as workshops on stress, ${ }^{26}$ physician awareness groups, ${ }^{27}$ and communication skills training, ${ }^{28}$ could prove helpful in burnout reduction among fellows.

Our study raises the question of whether the presence of burnout while in a fellowship places oncologists at risk for burnout later in their career, although the nature and driving factors of burnout in the fellowship may differ from those later on. Trainees are just beginning to establish themselves in a new professional identity; they have less experience and less confidence and, therefore, more stress in making recommendations to patients. Fellows may be more susceptible to burnout due to lack of oncologic or palliative care experience. They may have less PA because they have not had sufficient time to meet their professional goals and may just be recognizing the impact of a prolonged and demanding training on achieving their personal goals (eg, having a family or owning a home). Burnout later in one's career may be affected by financial considerations regarding salary, future reimbursements for service, targets for productivity, malpractice suits, and lack of intellectual stimulation, ${ }^{8,24,29}$ which are not likely issues among fellows.

Several limitations of the current study are apparent. Our sample may be biased, with disproportionately more fellows with burnout completing the survey. However, the high response rate and the comparable demographic characteristics of respondents and nonrespondents suggest that our results represent the experience of most fellows. We cannot determine that educational experiences, personal attitudes, or the hidden curriculum are causes of burnout; further research is needed to explore these intriguing associations. It is possible that fellows who are burned out answered all of the questions in a more negative fashion, including rating of the quality of the training, than did those who were not suffering from high levels of burnout. Thirdly, the information provided was self-rated, and we had no way to test the respondents' actual competencies. The utilization of single-item measures as predictor variables is an additional limitation. Finally, there is a 
TABLE 4 Oncology fellow responses associated with personal accomplishment

\begin{tabular}{|c|c|c|}
\hline & Mean \pm Std Dev & $\begin{array}{l}\text { I score, P-value } \\
\text { (bivariate) }\end{array}$ \\
\hline \multicolumn{3}{|l|}{ Location of medical school } \\
\hline United States $(n=124)$ & $37.9 \pm 6.5$ & \multirow{2}{*}{$\begin{aligned} t & =2.89 \\
P & =.0047\end{aligned}$} \\
\hline Non-US ( $\mathrm{n}=69)$ & $34.4 \pm 8.8$ & \\
\hline \multicolumn{3}{|c|}{$\begin{array}{l}\text { Influence of the death of a close friend or family member on the fellow's } \\
\text { practice of medicine }\end{array}$} \\
\hline Positive Influence ( $\mathrm{n}=139$ ) & $37.6 \pm 7.6$ & \multirow{2}{*}{$\begin{array}{l}t=3.31 \\
P=.0011\end{array}$} \\
\hline Negative or No Influence ( $n=33$ ) & $32.8 \pm 7.2$ & \\
\hline \multicolumn{3}{|c|}{$\begin{array}{l}\text { Physicians have a responsibility to help patients at the end of life to prepare } \\
\text { for death. }\end{array}$} \\
\hline Generally agree, Completely agree $(n=215)$ & $37.3 \pm 6.9$ & \multirow{2}{*}{$\begin{array}{l}t=-5.45 \\
P<.0001^{*}\end{array}$} \\
\hline Completely disagree, Generally disagree $(n=10)$ & $24.8 \pm 10.1$ & \\
\hline \multicolumn{3}{|c|}{$\begin{array}{l}\text { I dread having to deal with the emotional distress of family members of a } \\
\text { patient at the end of life. }\end{array}$} \\
\hline Completely disagree, Generally disagree $(n=155)$ & $38.0 \pm 6.8$ & \multirow{2}{*}{$\begin{array}{l}t=3.46 \\
P=.0008\end{array}$} \\
\hline Generally agree, Completely agree $(n=68)$ & $34.0 \pm 8.4$ & \\
\hline \multicolumn{3}{|l|}{ I feel guilty after a death. } \\
\hline Completely disagree, Generally disagree $(n=187)$ & $37.7 \pm 7.2$ & \multirow{2}{*}{$\begin{aligned} t & =3.83 \\
P & =0.0002\end{aligned}$} \\
\hline Generally agree, Completely agree (35) & $32.5 \pm 7.9$ & \\
\hline \multicolumn{3}{|c|}{ Faculty ability to discuss chemotherapy side effects (as perceived by the fellow) } \\
\hline Very Good, Excellent ( $\mathrm{n}=186$ ) & $37.4 \pm 6.6$ & \multirow{2}{*}{$\begin{aligned} t & =-3.00 \\
P & =.0026\end{aligned}$} \\
\hline Poor, Fair, Good ( $n=39)$ & $33.5 \pm 7.6$ & \\
\hline
\end{tabular}

Higher scores denote higher personal accomplishment (less burnout).

$P<.01$ was considered statistically significant.

* $=$ multivariate $P<.001$.

concern for type I errors from multiple analyses; to address this weakness, we used a more stringent $P$ value (.01).

Burnout is harmful at any point of one's career. Fellowship training programs need to recognize the high prevalence of burnout among their trainees. Our results demonstrate that, in addition to overall high quality teaching within the fellowship, teaching focused on providing fellows with the knowledge, skills, and attitudes specific to EOL care were associated with less burnout among oncology fellows. Further studies examining associations between burnout and other objective measures of program quality, eg, program compliance with the American College of Graduate Medical Education (ACGME) guidelines, recommended curricula, and pass rates on the oncology boards, would be valuable. Additionally, we found that personal attitudes about EOL care and the implicit values a program espouses and models around EOL may influence burnout levels. These findings provide concrete ideas for how fellowship programs might enhance their curricula in ways aimed at mitigating burnout. Studies examining whether some of the above inter- ventions are associated with lower burnout among fellows and later in one's career would help determine if these approaches are effective at preventing burnout among oncology fellows and practicing oncologists. Additionally, longitudinal studies looking at the relationship between burnout as a fellow and burnout later in one's career are needed.

\section{References}

1. Burnout. Merriam-Webster. http://www.merriam-webster.com/ dictionary/burnout. 2012. Accessed July 31, 2011.

2. Maslach C, Schaufeli WB, Leiter MP. Job burnout. Annu Rev Psychol. 2001;52:397-422.

3. Maslach C, Jackson SE, Leiter MP. Maslach Burnout Inventory Manual. 3rd ed. Palo Alto, CA: Consulting Psychologists Press; 1996.

4. Gundersen L. Physician burnout. Ann Intern Med. 2001;135(2): 145-148.

5. Felton JS. Burnout as a clinical entity - its importance in health care workers. Occup Med (Lond). 1998;48(4):237-250.

6. Shanafelt TD, Bradley KA, Wipf JE, Back AL. Burnout and self-reported patient care in an internal medicine residency program. Ann Intern Med. 2002;136(5):358-367.

7. Dyrbye LN, Massie FS Jr, Eacker A, et al. Relationship between burnout and professional conduct and attitudes among US medical students. JAMA. 2010;304(11):1173-1180. 
8. Whippen DA, Canellos GP. Burnout syndrome in the practice of oncology: results of a random survey of 1,000 oncologists. J Clin Oncol. 1991;9(10):1916-1920.

9. Blanchard P, Truchot D, Albiges-Sauvin L, et al. Prevalence and causes of burnout amongst oncology residents: a comprehensive nationwide cross-sectional study. Eur J Cancer. 2010;46(15):27082715.

10. Glasberg J, Horiuti L, Novais MA, et al. Prevalence of the burnout syndrome among Brazilian medical oncologists. Rev Assoc Med Bras. 2007;53(1):85-89.

11. Grunfeld E, Whelan TJ, Zitzelsberger L, Willan AR, Montesanto B, Evans WK. Cancer care workers in Ontario: prevalence of burnout, job stress and job satisfaction. CMAJ. 2000;163(2):166169.

12. Whippen DA, Zuckerman EL, Andersen JW, Kamin DY, Holland JC. Burnout in the practice of oncology: Results of a follow-up survey. J Clin Oncol. 2004;22(14S):6053.

13. Kash KM, Holland JC, Breitbart W, et al. Stress and burnout in oncology. Oncology (Williston Park). 2000;14(11):1621-1633; discussion 1633-1634, 1636-1637.

14. Catalan J, Burgess A, Pergami A, Hulme N, Gazzard B, Phillips R. The psychological impact on staff of caring for people with serious diseases: the case of HIV infection and oncology. J Psychosom Res. 1996;40(4):425-435.

15. Embriaco N, Azoulay E, Barrau K, et al. High level of burnout in intensivists: prevalence and associated factors. Am J Respir Crit Care Med. 2007;175(7):686-692.

16. Graham J, Ramirez AJ, Cull A, Finlay I, Hoy A, Richards MA. Job stress and satisfaction among palliative physicians. Palliat Med. 1996;10(3):185-194.

17. Ramirez AJ, Graham J, Richards MA, Cull A, Gregory WM. Mental health of hospital consultants: the effects of stress and satisfaction at work. Lancet. 1996;347(9003):724-728.

18. Ramirez AJ, Graham J, Richards MA, et al. Burnout and psychiatric disorder among cancer clinicians. Br J Cancer. 1995;71(6): 1263-1269.
19. Fallowfield L, Jenkins V, Farewell V, Saul J, Duffy A, Eves R. Efficacy of a Cancer Research UK communication skills training model for oncologists: a randomised controlled trial. Lancet. 2002; 359(9307):650-656.

20. Fallowfield L, Jenkins V, Farewell V, Solis-Trapala I. Enduring impact of communication skills training: results of a 12 -month follow-up. Br J Cancer. 2003;89(8):1445-1449.

21. Kearney MK, Weininger RB, Vachon ML, Harrison RL, Mount $\mathrm{BM}$. Self-care of physicians caring for patients at the end of life: "Being connected. . . a key to my survival". JAMA. 2009;301(11): 1155-1164, E1.

22. Buss MK, Lessen DS, Sullivan AM, Von Roenn J, Arnold RM, Block SD. Hematology/oncology fellows' training in palliative care: results of a national survey. Cancer. 2011;117(18):43044311.

23. Sullivan AM, Lakoma MD, Block SD. The status of medical education in end-of-life care: a national report. J Gen Intern Med. 2003;18(9):685-695.

24. Allegra CJ, Hall R, Yothers G. Prevalence of burnout in the u.s. Oncology community: results of a 2003 survey. J Oncol Pract. 2005; 1(4):140-147.

25. Jackson VA, Mack J, Matsuyama R, et al. A qualitative study of oncologists' approaches to end-of-life care. J Palliat Med. 2008; 11(6):893-906

26. Armstrong J, Lederberg M, Holland J. Fellows' forum: a workshop on the stresses of being an oncologist. J Cancer Educ. 2004;19(2): 88-90.

27. Sekeres MA, Chernoff M, Lynch TJ Jr, Kasendorf EI, Lasser DH, Greenberg DB. The impact of a physician awareness group and the first year of training on hematology-oncology fellows. J Clin Oncol. 2003;21(19):3676-3682.

28. Baile WF, Kudelka AP, Beale EA, et al. Communication skills training in oncology. Description and preliminary outcomes of workshops on breaking bad news and managing patient reactions to illness. Cancer. 1999;86(5):887-897.

29. Shanafelt T, Dyrbye L. Oncologist burnout: causes, consequences, and responses. J Clin Oncol. 2012;30(11):1235-1241. 